\title{
ALICATA DISEASE
}

\section{Neuroinfestation by Angiostrongylus cantonensis in Recife, Pernambuco, Brazil}

\author{
Ana Rosa Melo Correa Lima', Solange Dornelas Mesquita', Silvana Sobreira Santos', \\ Eduardo Raniere Pessoa de Aquino', Luana da Rocha Samico Rosa $a^{3}$, Fábio Souza Duarte, \\ Alessandra Oliveira Teixeira', Zenize Rocha da Silva Costa ${ }^{4}$, Maria Lúcia Brito Ferreira ${ }^{5}$
}

Angiostrongylus cantonensis, is a nematode in the Secernentea class, Strongylidae order, Metastrongylidæe superfamily and Angiostrongylidæ family', and is the most common cause of human eosinophilic meningitis worldwide. This parasite has rats and other mammals as definitive hosts and snails, freshwater shrimp, fish, frogs and monitor lizards as intermediate hosts'. Mammals are infected by ingestion of intermediate hosts and raw/undercooked snails or vegetables, containing third-stage larvae ${ }^{2}$. Once infested, the larvae penetrate the vasculature of the intestinal tract and promote an inflammatory reaction with eosinophilia and lymphocytosis. This produces rupture of the bloodbrain barrier, changes to nervous tissue and damage to the Purkinje cells in the cerebellum, thereby promoting eosinophilic meningoencephalitis or Alicata disease ${ }^{3}$.

A. cantonensis has been found in Southeast Asia and the South Pacific, where it is endemic ${ }^{2}$, as well as in Africa, India, Caribbean, Australia, North America, Jamaica, Haiti, Cuba, Puerto Rico ${ }^{3}$ and Brazil ${ }^{4}$.

\section{CASE}

A female from Olinda, Pernambuco, Brazil, who was born on April 27, 1982, was seen in the neurological emergency room of Hospital da Restauração on May 24, 2008. The person accom- panying the patient reported that she had presented a rash associated with joint pain, followed by progressive difficulty in walking for 30 days, which was associated with sleepiness over the last 15 days.

In the patient's past history, there were references to mental retardation and lack of ability to understanding simple orders. She presented independent gait and had frequently run away from home into the surrounding area. There was mention of involuntary movements, predominantly of the upper limbs, which intensified after the change of health status that motivated the current search for medical assistance. In November 2007, the patient presented with generalized tonic-clonic seizures and was medicated with carbamazepine, $200 \mathrm{mg} /$ twice a day.

On clinical examination, the patient was febrile and had erythema and heat in her right knee. On neurological examination, the patient was comatose, with Glasgow index 8 , tonic deviation of the head and gazing to the right, associated with intermittent masticatory movements, suggestive of seizures. There were also choreoathetotic movements of the upper limbs. The ocular fundi were normal. There was no resistance to neck movement. She presented flaccid paraplegia, which was associated with Ashworth grade 2 hypertonia in the upper limbs that was more evident on the right side. Reflex examination showed absence of knee reflex, normal adductor and Achilles reflex, indifferent cutaneous-plantar reflex and brisk upper-limb reflex.

Table 1. Results from additional tests for diagnosis.

\begin{tabular}{lll}
\hline & $\begin{array}{l}\text { Complementary } \\
\text { tests }\end{array}$ & Findings \\
\hline $05 / 28 / 2008$ & $\begin{array}{l}\text { Leukogram for } \\
\text { confirmation }\end{array}$ & $\begin{array}{l}\text { Overall leukocyte count }=15.760 \text { cells } / \mathrm{mm}^{3} \\
\text { Specific leukocyte count: neutrophils } 66 \% \text {, eosinophils } 12.8 \% \text {, basophils } 0 \% \text {, typical lymphocytes } \\
15 \%, \text { monocytes } 4.6 \%\end{array}$ \\
& & Cell count $=168.66$ cells $/ \mathrm{mm}^{3} ;$ eosinophils $=87 \% ;$ protein=41 mg/dL; glucose $=52 \mathrm{mg} / \mathrm{dL} ; \mathrm{ADA}=3.9 \mathrm{lU} / \mathrm{I}$ \\
\hline
\end{tabular}

DOENÇA DE ALICATA: NEUROINFESTAÇÃO POR Angiostrongylus cantonensis EM RECIFE, PERNAMBUCO, BRASIL.

Neurology Service of Hospital da Restauração, Recife PE, Brazil: ${ }^{N}$ Neurologist; ${ }^{2}$ Neurologist and Liquorologist; ${ }^{3}$ Neurology Resident; ${ }^{4}$ Nurse Coordinator of Meningitis Program of Health Department of Pernambuco State, Recife PE, Brazil; ${ }^{5}$ Chairwoman Neurologist.

Received 3 July 2009, received in final form 4 August 2009. Accepted 24 September 2009.

Dra. Maria Lúcia Brito Ferreira - Rua Neto de Mendonça 230 / 802 -52050-100 Recife PE - Brasil. E-mail: lucabrito@uol.com.br 
Table 2. Results of the second battery of complementary tests for diagnosis.

\begin{tabular}{|c|c|c|}
\hline Date & $\begin{array}{l}\text { Complementary } \\
\text { tests }\end{array}$ & Findings \\
\hline \multirow[t]{7}{*}{$06 / 11 / 2008$} & CSF test & Cell count= 197.33 cells $/ \mathrm{mm}^{3}$; eosinophils=39\%; protein $=36 \mathrm{mg} / \mathrm{dL}$; glucose $=58 \mathrm{mg} / \mathrm{dL}$ \\
\hline & & China ink=negative \\
\hline & & Crypto-latex=unreactive \\
\hline & & VDRL=unreactive \\
\hline & & Reactions for diagnosing cytomegalovirus, Epstein-Barr virus, herpes virus, HIV and HTLV=unreactive \\
\hline & & Reactions for diagnosing cysticercosis, schistosomiasis and toxoplasmosis= unreactive \\
\hline & & Polymerase chain reaction for Angiostrongylus cantonensis - positive \\
\hline $06 / 15 / 2008$ & Brain MRI & $\begin{array}{l}\text { In Flair, bilateral and symmetrical signal abnormality in head of caudate nucleus and putamen, } \\
\text { characteristic of edema, associated to pan-sinusopathy. Absence of anomalous meninx impregnation }\end{array}$ \\
\hline
\end{tabular}

Table 3. Results of the third battery of additional tests for clinical follow-up.

\begin{tabular}{lll}
\hline & $\begin{array}{l}\text { Complementary } \\
\text { tests }\end{array}$ & Findings \\
\hline $07 / 02 / 2008$ & CSF test & Cell count=10.66 cells $/ \mathrm{mm}^{3} ;$ eosinophils=0\%; protein=39 $\mathrm{mg} / \mathrm{dL} ;$ glucose=63 mg/dL \\
$08 / 08 / 2008$ & CSF test & Cell count=24 cells $/ \mathrm{mm}^{3}$; eosinophils=36\%; protein=33 mg/dL; glucose=59 mg/dL; ADA=1.7 IU $/ \mathrm{l}$ \\
$09 / 21 / 2008$ & Brain MRI & Dilatation of ventricular system. Absence of anomalous meninx impregnation \\
\hline
\end{tabular}

The overall leukocyte count on admission was 13,380 cells/ $\mathrm{mm}^{3}$, consisting of: $48.9 \%$ neutrophils, $20 \%$ eosinophils, $0 \%$ basophils, $22.4 \%$ typical lymphocytes and $8.4 \%$ monocytes.

The diagnostic hypotheses, based on the history, neurological examination and leukocyte count were meningo-encephaloradiculoneuritis of infectious or inflammatory etiology, or acute disseminated encephalomyelitis (ADEM). The patient was admitted to the ward for more detailed investigation by means of additional tests (Table 1).

The spinal fluid eosinophils associated with marked eosinophilia provided the basis for diagnosing neuroinfestation, for which new additional tests were requested (Table 2 ).

The patient's symptoms worsened and she was transferred to the intensive care unit, where she received assisted ventilation.

In parallel, through the Ministry of Health, the Epidemiological Surveillance Division of the Environmental Health Department of Pernambuco was mobilized to carry out an active search in the vicinity of the patient's home. The surveillance technicians located and collected adult snails of the species Achantina fulica. The snails were sent to Fiocruz, Rio de Janeiro, Brazil, for infestations to be investigated. A sample of the patient's cerebrospinal fluid was sent to the Molecular Parasitology Laboratory and Parasitic Biology Laboratory of the Institute of Biomedical Research and School of Biosciences, Pontifícia Universidade Católica of Rio Grande do Sul, for further investigation.

The results and the finding of snails suggested the diagnostic hypothesis of parasitic eosinophilic meningo-encephalo-radiculoneuritis. Treatment with methylprednisolone $1 \mathrm{~g} /$ day for 5 days, and ivermectin $6 \mathrm{mg} / 2$ tablets/day in a single dose was instituted. Carbamazepine was replaced by valproic acid $500 \mathrm{mg}$, 2 tablets/day, because of the possibility of drug interaction.

The results from the additional tests for clinical follow-up are shown in Table 3.

On August 4, 2008, the diagnosis of neuroinfestation by Angiostrongylus cantonensis was made because of positive findings in CSF shown by the real-time polymerase chain reaction.

The patient presented an improvement in clinical consciousness level, and her knee reflex reappeared. However, the flaccid paraplegia remained, with accentuation of the previous choreoathetotic movements and ankylosis in the right knee, with a limitation of 90 degrees of flexion.

To investigate the possibility of nerve root involvement, because of the presence of areflexia and flaccid paraplegia, the patient underwent upper and lower-limb electromyography. This was suggestive of subacute symmetrical sensory-motor axonal polyneuropathy, associated with active reinnervation and radicular involvement, as shown by lumbosacral paravertebral muscle fasciculation and fibrillation.

The patient then presented clinical worsening and died on October 5, 2008.

\section{DISCUSSION}

The clinical manifestations of angiostrongyloidiasis are similar to the symptoms and signs of meningitis or radiculomyeloencephalitis. For example, there may be headache, vomiting, paresthesia, weakness and, occasionally, visual disturbances and paralysis of the ocular extrinsic muscles ${ }^{2,5}$. As noted in this case, eosinophilic pleocytosis 


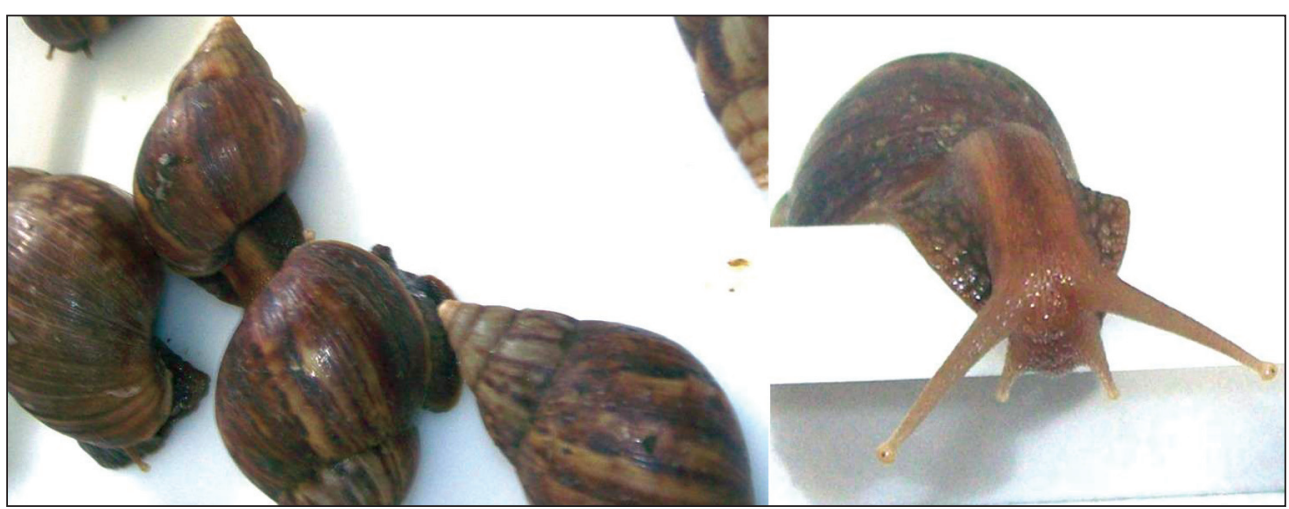

Figure. Examples of Achantina fulica infested by A. cantonensis and detail of head region.

is associated with this because of parasite migration to the spinal cord and cranial nerves ${ }^{5}$. This occurs under the action of interleukin 5 , which stimulates the maturation of eosinophil function and acts as a potent and selective eosinophil chemotaxis factor ${ }^{6}$.

Spinal fluid eosinophils associated with a history of exposure to larval infestation should be the basis of the presumptive diagnosis of eosinophilic meningoencephalitis. This is defined as the presence of 10 or more eosinophils $/ \mathrm{mm}^{3}$ in CSF or spinal fluid eosinophils representing at least $10 \%$ of the total spinal fluid leukocytes. The causes of eosinophilic meningoencephalitis may be parasitic, fungal, bacterial, viral, rickettsial, malignant, drugrelated or hypereosinophilic. This range of causes justified the additional tests required in this case. The results from the tests ruled out the non-infectious and infectious hypotheses, and left the identification of the parasite agent.

In this case, magnetic resonance images only reinforced the clinical evidence of meningoencephalitis. This corroborated the findings of Jin et al. ${ }^{6}$ that MRI is not specific and that clinical and epidemiological characteristics should be considered more important. However, we must emphasize that MRI changes may reflect edema caused by the immune process, triggered by the presence of parasite larvae in the brain. This process includes: (a) increased synthesis of eotaxin (especially eotaxin-2), a chemokine that increases blood eosinophil chemotaxis to the brain, (b) intrathecal synthesis of IgE that attaches to the wall of L3stage larvae and facilitates the binding of eosinophils that secrete enzymes to destroy the parasite ${ }^{7}$, (c) eosinophilic enzyme action on nervous tissue, stimulating edema ${ }^{8}$.

Because there was mention in the patient's history of leaks around the home, we sought to investigate the presence of Achantina fulica in the vicinity, since this mollusc is the parasite's definitive host. The positive finding from the polymerase chain reaction for $A$. cantonensis in CSF and the isolation of parasites in the snails (Figure) helped to establish a definitive diagnosis.
It should be emphasized that notifying the Environmental Surveillance Division regarding this neuroinfestation was important as a preventive public health measure for the community where the patient lived, given the severity of this infestation and the possibility that the parasite might spread.

The hypotheses of infectious or inflammatory meningo-encephalo-radiculoneuritis, or acute disseminated encephalomyelitis (ADEM), led us to administer a methylprednisolone pulse, in an attempt to reduce the inflammatory process and improve the patient's neurological symptoms. An oral ivermectin regimen was instituted, because Brazil is a country with high prevalence of strongyloidiasis. The latter is caused by an intestinal parasite that can be exacerbated by the use of steroids, through two mechanisms: activation of the parasite's ecdysteroid receptors, thereby increasing its virulence; or reduction of the immune response mediated by $T$ cells, thereby facilitating the spread of the parasite to the central nervous system?. Ivermectin is the drug of choice for treating strongyloidiasis because it has fewer adverse effects than shown by albendazole or thiabendazole, and higher rates of larval clearance $^{10}$. This aspect of treatment deserves emphasis, because it helped the patient, since the ivermectin is also indicated for treating infestation by $A$. cantonensis.

The methylprednisolone pulse and ivermectin administration may have been responsible for the absence of spinal fluid eosinophils in subsequent CSF tests, as a fleeting effect and transient improvement, because high levels of spinal fluid eosinophils appeared again in other CSF tests, at levels compatible with previous levels.

Although there was a mild improvement in symptoms after drug therapy was instituted, the patient died five months after the start of symptoms. The clinical forms of angiostrongyloidiasis are eosinophilic meningitis, eosinophilic encephalitis and ocular angiostrongyliasis. These seem to derive from the spontaneous death of adult parasites, which promote severe inflammation in organs that they infect. Over $90 \%$ of cases develop eosinophilic men- 
ingitis. Eosinophilic encephalitis affects less than $10 \%$ of cases and is usually fatal", which may explain this death.

In summary, this report of meningo-encephalo-radiculoneuritis due to $A$. cantonensis in northeastern Brazil was the finding of the etiological agent in infested snails. The main objective of this report was to alert general physicians and neurologists to the need to pay special attention to spinal fluid eosinophil counts or marked blood eosinophilia. This is especially important in the presence of neurological symptoms and signs associated with the epidemiological aspects of the patient's environment, which may facilitate the identification of the etiological agent.

\section{REFERENCES}

1. Hüttemann M, Schmahl G, Mehlhorn H. Light and electron microscopic studies on two nematodes, Angiostrongylus cantonensis and Trichuris muris, differing in their mode of nutrition. Parasitol Res 2007;103(Suppl 2):S225-S232.

2. Baheti NN, Sreedharan M, Krishnamoorthy T, Nair MD, Radhakrishanan K. Eosinophilic meningitis and an ocular worm in a patient from Kerala, South India. J Neurol Neurosurg Psychiatry 2008;79:271.

3. Kliks MM, Palumbo NE. Eosinophilic meningitis beyond the Pacific Basin: the global dispersal of a peridomestic zoonosis caused by $\mathrm{An}$ - giostrongylus cantonensis, the nematode lungworm of rats. Soc Sci Med 1992;34:199-212.

4. Caldeira RL, Mendonça CLGF, Goveia CO, et al. First record of molluscs naturally infected with Angiostrongylus cantonensis (Chen, 1935) (Nematoda: Metastrongylidae) in Brazil. Mem Inst Oswaldo Cruz Rio de Janeiro 2007;102:887-889.

5. Intapan PM, Kittimongkolma S, Niwattayakul K, Sawanyawisuth K, Maleewong W. Cerebrospinal fluid cytokine responses in human eosinophilic meningitis associated with angiostrongyliasis. J Neurolol Sci 2008;267:17-21.

6. Jin EH, Ma Q, Ma DQ, He W, Ji AP, Yin CH. Magnetic resonance imaging of eosinophilic meningoencephalitis caused by Angiostrongylus cantonensis following eating freshwater snails. Chin Med J 2008;121:67-72.

7. Padilla-Docal B, Dorta-Contreras AJ, Bu-Coifiu-Fanego R, et al. Intrathecal synthesis of IgE in children with eosinophilic meningoencephalitis caused by Angiostrongylus cantonensis. Cerebrospinal Fluid Res 2008;5:18-22.

8. Dorta-Contreras AJ, Núñez-Fernández FA, Pérez-Martin O, et al. Peculiaridades de la meningoencefalitis por Angiostrongylus cantonensis en América. Rev Neurol 2007;45:755-763.

9. Mora CS, Segami MI, Hidalgo JA. Strongyloides stercoralis hyperinfection in systemic lupus erythematosus and the antiphospholipid syndrome. Semin Arthritis Rheum 2006;36:135-143.

10. Pacanowski J, Santos M, Roux A, et al. Subcutaneous ivermectin as a safe salvage therapy in Strongyloides stercoralis hyperinfection syndrome: a case report. Am J Trop Med Hyg 2005;73:122-124.

11. Sawanyawisuth K, Sawanyawisuth K. Treatment of angiostrongyliasis. Trans R Soc Trop Med Hyg 2008;101:1-7. 